International Journal of Environment, Agriculture and Biotechnology
Vol-6, Issue-6; Nov-Dec, 2021
Journal Home Page Available: https://ijeab.com/
Journal DOI: $10.22161 /$ ijeab

Peer Reviewed

\title{
Toxic Test of Lavender Leaf (Lavandula angustifolia) Ethanol Extract as Biolarvicide for Aedes aegypti Mosquitoes Vectors of Dengue Hemorrhagic Fever
}

\author{
Alfrits Komansilan ${ }^{1}$, Ni Wayan Suriani², Reinhard Komansilan ${ }^{3, *}$ \\ ${ }^{1}$ Department of Physics, Faculty of Mathematics and Natural Sciences, Manado State University, Indonesia \\ ${ }^{2}$ Department of Science Education, Faculty of Mathematics and Natural Sciences, Manado State University, Indonesia \\ ${ }^{3}$ Department of Informatics Engineering, Faculty of Engineering, University of Sam Ratulangi Manado, Indonesia \\ Corresponding Author
}

Received: 30 Oct 2021; Received in revised form: 10 Dec 2021; Accepted: 16 Dec 2021; Available online: 23 Dec 2021 (C)2021 The Author(s). Published by Infogain Publication. This is an open access article under the CC BY license (https://creativecommons.org/licenses/by/4.0/).

\begin{abstract}
Toxic test of ethanolic extract of lavender (Lavandula angustifolia) leaf on mortality of Aedes aegypti mosquito larvae as vector of dengue hemorrhagic fever has been completed. The aim of the study was to determine the effective concentration of lavender (Lavandula angustifolia) leaf ethanol extract against the mortality of Aedes aegypti and $L C_{50}$ mosquitoes for 24 hours. This study used a completely randomized design with 5 extract treatments, namely: 10ppm; 50ppm; 100ppm; 500ppm and 1000ppm and 1 control group with 3 replications. The results of the study were analyzed using one-way analysis of variance. and continued with the $B N T$ test at a significance level of 0.05. The results showed that the ethanolic extract of lavender (Lavandula angustifolia) leaves was toxic to the larvae of the Aeders aegypti mosquito, which was indicated by the increasing number of larval mortality. Based on the test results, the concentration of 500 ppm lavender leaf ethanol extract was able to kill 100\% of mosquitoes, and the effective concentration to kill 50\% of test mosquito larvae was $87.0285 \mathrm{ppm}$. The ethanol extract of lavender (Lavandula angustifolia) leaves has the potential to be developed as a biolarvicide for the Aedes aegypti mosquito vector of dengue hemorrhagic fever.
\end{abstract}

Keywords_L Lavandula angustifolia leaves, biolarvicides, Aedes aegypti.

\section{INTRODUCTION}

North Sulawesi in January 2015 was categorized as an Extraordinary Event (KLB), the five-year cycle of the Dengue Hemorrhagic Fever (DHF) outbreak that hit eight districts/cities in North Sulawesi, killing eight people who were positive for the virus transmitted by the Aides aegypti mosquito.

Until now, no vaccine has been found to kill the virus that causes dengue fever. One way to prevent the spread of dengue hemorrhagic fever (DHF) is to prevent dengue virus transmission, namely by controlling and eradicating vectors to cut off disease transmission. (WHO, 2005).

Fogging is one of the mechanical control methods. Unfortunately, smoking is considered less effective because it tends to repel mosquitoes from their nests, not kill them. The chemical method used is the spread of larvicides such as abate in mosquito breeding places. Indeed, the use of chemical larvicides has succeeded in controlling Aedes aegypti larvae, but the continuous use of chemical larvicides will actually cause resistance and various environmental problems. cause environmental pollution, poisoning, death of non-target organisms, and produce residues.

Due to the negative impact caused by chemical insecticides, it has encouraged experts to look for alternatives to vector eradication, namely by using natural insecticides that are safer, easier, cheaper, and do not have a toxic impact on humans. 
Plants that have been isolated by researchers containing active compounds of vegetable insecticides in Aedes aegypti mosquito larvae are soursop seeds (Annona muricata) with $\mathrm{LC}_{50}=117.27 \mathrm{ppm}$ (Komansilan et al. 2012), Hutun seeds (Barringtonia asiatica Kurz) with Lethal Concentration $\mathrm{LC}_{50}=35.72 \mathrm{ppm}$ (Komansilan and Suriani. 2016) and tuba root (Derris elliptica) with Lethal Concentration $\mathrm{LC}_{50}=44.7526 \mathrm{ppm}$ (Komansilan et al. 2017).

Lavender (Lavandula angustifolia) is one of the plants that can be used as a natural insecticide, because it is effective in controlling insects (mosquitoes). This is because lavender plants have kairomone as a chemical that causes an odor that mosquitoes don't like. Lavender plants also have active ingredients in the form of flavonoids; Rosmarinic acid, Chlorogenic acid, Caffeic acid 2-(3,4 dihydroxyphenyl) ethenyl ester (found in flowers), Flavonoids; Hypolaetin, Scutellarein, Salvigenin, Malvidin, Xanthomicrol, Delphinidine (found in leaves), and Terpenoi; Linalil acetate, Linalol, 1,8-

Cineole, Camphor, Ursolic acid, Oleanolic acid which acts as a repellent (insect repellent) by working as a contact poison and respiratory poison (Kherissat, 2009).

Based on research from Lekitoo (2009), it is known that the flowers and leaves of the lavender plant (Lavandula angustifolia) have no statistically different effect as a repellent against the Aedes aegypti mosquito.

Regarding the toxicity of lavender (Lavandula angostifolia) leaf extract, the results of research from Nindatu, et al. (2011) showed that lavender (Lavandula angostifolia) leaf extract was good and effective for controlling Culex sp mosquitoes, with an $\mathrm{LC}_{50}$ value of $0.259 \%$

This study aims to determine the toxicity of the ethanolic extract of lavender (Lavandula angustifolia) leaves as a biolarvicide to the Aedes aegypti mosquito vector of dengue hemorrhagic fever.

\section{RESEARCH METHODS}

\section{Location of Research Time}

This research was conducted at the Integrated Science Laboratory, Faculty of Mathematics and Natural Sciences, Manado State University. This research was conducted from May to September 2021

\section{Tools and Materials}

The tools used are: vial, mosquito cage, blender, buchner, rotary evaporator, desiccator, digital scale, measuring cup and micro pipette. Research materials: Lavender leaves, ethanol, aquades, Aedes aegypti mosquito larvae, fish feed, filter paper .

\section{Research design}

The design used was a completely randomized design (CRD), with 6 treatments and 3 replications, namely: $\mathrm{K} 1=$ Control, K2 = .10ppm, K3 = .50ppm, K4 = 100ppm, K5 = $500 \mathrm{ppm}$ and $\mathrm{K} 6=1000 \mathrm{ppm}$

\section{Observation}

The parameter observed was the mortality percentage of Aedes aegypti mosquito larvae, which was calculated using the formula proposed by Kundra (1981):

$$
M=\mathbf{a} / \mathbf{b} \times 100 \%
$$

Where: $\mathrm{M}=$ percentage of mosquito mortality Ae. aegypti

$$
\begin{aligned}
& \mathrm{a}=\text { number of mosquitoes Ae. Aegypti Dead } \\
& \mathrm{b}=\text { number of mosquitoes Ae. aegypti who }
\end{aligned}
$$
used.

\section{Work procedures}

\section{Reproduction of Aedes aegypti mosquito larvae}

a) Aedes aegypti mosquito larvae media is made by filling a plastic container with water and the inner wall is lined with filter paper. Filter paper serves as a place for female mosquitoes to attach their eggs.

b) Eggs attached to filter paper are then dried at room temperature and stored in a closed container. For hatching eggs, filter paper is dipped in a plastic tray filled with water and after 24 hours the eggs will hatch and grow into first instar larvae.

c) First instar larvae will develop into second, third (4 days) and IV instar (2 days) instar larvae. Once every 2 days, the larvae were fed 1-2 grams of fish pellets. III/IV instar larvae used in the test.

\section{Extract Making}

The manufacture of lavender leaf extract is as follows:

a) Lavender leaves are separated from the stems, washed, and air-dried to dry indoors and away from sunlight.

b) The dried lavender leaves are mashed using a blender.

c) The mashed leaves were extracted by maceration using technical ethanol until all the components had been extracted.

d) The ethanol extract obtained was evaporated with a vacuum rotary evaporator until all solvent evaporated. 


\section{Toxicity Test.}

a) Provide a solution of lavender leaf extract (Lavandula angustifolia) in a vial with concentrations of: 0ppm, 10ppm, 50ppm, 100ppm, 500ppm and 1000ppm.

b) In each vial, 10 larvae of Aedes aegypti mosquitoes were inserted with 3 replications

c) The calculation of mortality was carried out after 24 hours of treatment.

d) In the control tube using plain water.

\section{Data analysis}

The toxicity of lavender leaf extract to Aedes aegypti mosquito larvae was determined based on the $\mathrm{LC}_{50}$ value, namely the concentration where the test larvae died by $50 \%$. Determination of $\mathrm{LC}_{50}$ was carried out using probit analysis. To distinguish the toxicity between treatments of several concentrations of lavender leaf extract against Aedes aegypti mosquito larvae, it was analyzed using oneway ANOVA analysis at a 95\% confidence level $(\alpha=$ 0.05), followed by the BNT test.

\section{RESULTS AND DISCUSSION}

Based on mortality data of Aedes mosquito larvae that were tested for 24 hours with lavender leaf extract (Lavandula angustifolia), the average mortality obtained is presented in table 1 .

Table 1. Average Mortality of Aedes aegypti Mosquito

Larvae Testing With Lavender Leaf Extract (Lavandula angustifolia) For 24 Hours.

\begin{tabular}{cc}
\hline $\begin{array}{c}\text { Test Concentration } \\
(\mathbf{p p m})\end{array}$ & $\begin{array}{c}\text { Average } \\
\text { Mortality }(\boldsymbol{\%})\end{array}$ \\
\hline Control & 0 \\
10 & 3.33 \\
50 & 23.33 \\
100 & 60 \\
500 & 100 \\
1000 & 100 \\
\hline
\end{tabular}

According to table 1, it can be seen that the average mosquito mortality at the lowest concentration, namely the $10 \mathrm{ppm}$ treatment was only able to kill $3.33 \%$ of the number of mosquito larvae tested and the 50ppm concentration treatment was able to kill $23.33 \%$ of the number of mosquito larvae tested. Furthermore, in the treatment with a concentration of $100 \mathrm{ppm}$ the mortality of mortality was good, reaching $60 \%$ of the number of mosquitoes tested. While at concentrations of 500ppm and 1000 ppm mortality mortality of Aedes aegypti mosquito larvae has reached $100 \%$. \%. The mortality data of Aedes aegypti mosquito larvae can be seen in the histogram in Figure 1.

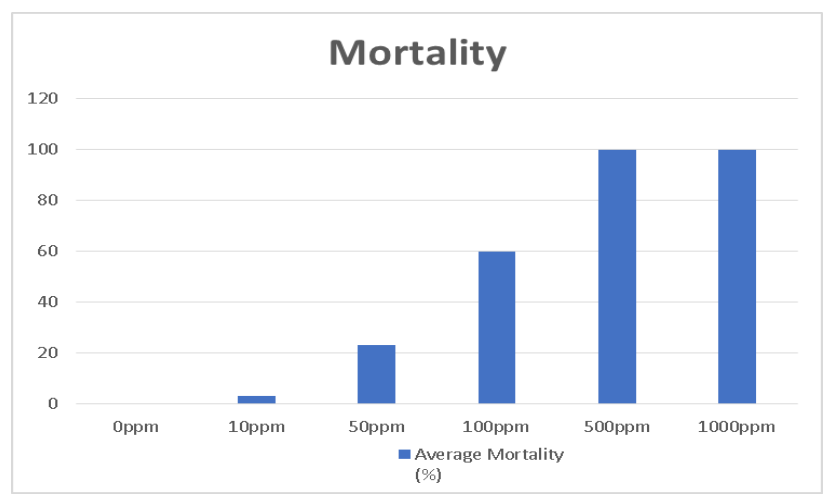

Fig.1. Histogram of Average Mortality of Larvae Ae. aegypti For 24 Hours Treatment with Lavender Leaf Extract (Lavandula angustifolia).

Furthermore, based on one-way analysis of variance of the toxicity of the ethanolic extract of lavender leaves on the mortality of Ae. aegypti data can be seen in table 2 .

Table 2. Results of one-way analysis of variance on the toxicity of lavender leaf extract (Lavender angustifolia) on mortality of Ae. aegypti after 24 hours of treatment.

ANOVA

Death Rate

\begin{tabular}{lr|r|r|r|r} 
& Sum of Squares & df & Mean Square & F & \multicolumn{1}{c}{ Sig. } \\
\hline Between Groups & 313.778 & 5 & 62.756 & 225.920 & .000 \\
\hline Within Groups & 3.333 & 12 & .278 & & \\
\hline Total & 317.111 & 17 & & & \\
\hline
\end{tabular}


From the results of one-way analysis of variance (ANOVA) in table 2, it shows that the calculated $\mathrm{F}$ value $>$ table $\mathrm{F}(\mathrm{P}<=0.05)$. This means that the treatment given has a significant effect on the mortality of Ae. aegypti. Furthermore, to determine the toxicity of lavender (Lavender angustifolia) leaf extract which was significantly different to the mortality of Ae. aegypti, data analysis was continued with the Least Significant Difference (BNT) test using the SPSS for windows 15.0 program.

From the results of the BNT test shown in the table above, it shows that the control is not significantly different from a concentration of $10 \mathrm{ppm}$, but significantly different from $50,100,500$ and $1000 \mathrm{ppm}$. The concentration of $10 \mathrm{ppm}$ is not significantly different from $0 \mathrm{ppm}$, but significantly different from 50, 100, 500 and 1000ppm. As for the concentrations of 50ppm 100ppm, 500ppm and 1000ppm, all of them looked significantly different both to the control and between treatments.

Based on the results of the calculation of the average mortality data and the BNT test, it can be seen that at all concentrations used, the higher the concentration of lavender leaf extract, the higher the mortality percentage of Ae. Aegypti as in Figure 2.

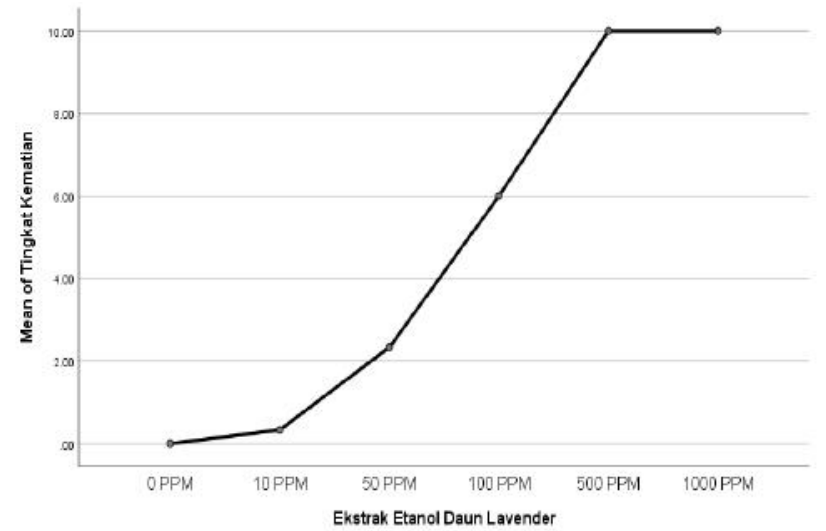

Fig.2. Graph of the relationship between the concentration of lavender leaf extract (Lavandula angustifolia) and mortality of Ae. Aegypti

Based on the results of the BNT test, probit analysis was carried out to determine the $\mathrm{LC}_{50}$ value of the effective concentration of lavender leaf extract (Lavandula angustifolia). kill $50 \%$ of Ae. aegypti which was tested for 24 hours, the data were analyzed using Probit Analysis (Finney Method) using Minitab 17 software.

The data used as a whole were obtained from 10 larvae of Ae. aegypti in each replication (there were 3 replications) so that 30 larvae of Ae. aegypti as a whole. Table 3. below presents the estimation parameters of the probit analysis model:

Table 3. Parameters of the estimated probit analysis model of clove leaf extract on Ae. aegypti larva larvae

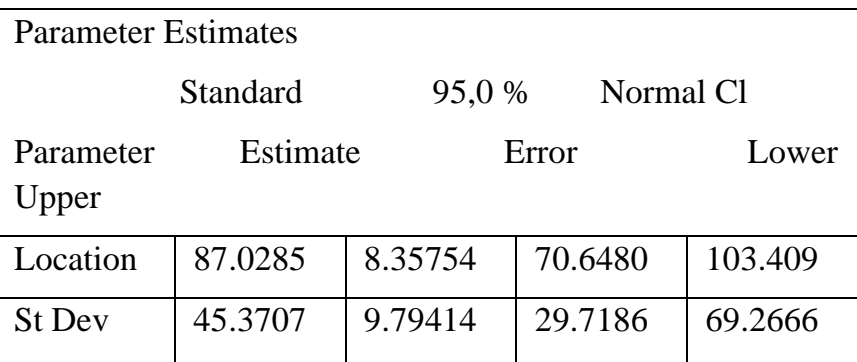

Graphically, the probit analysis curve is presented as follows:

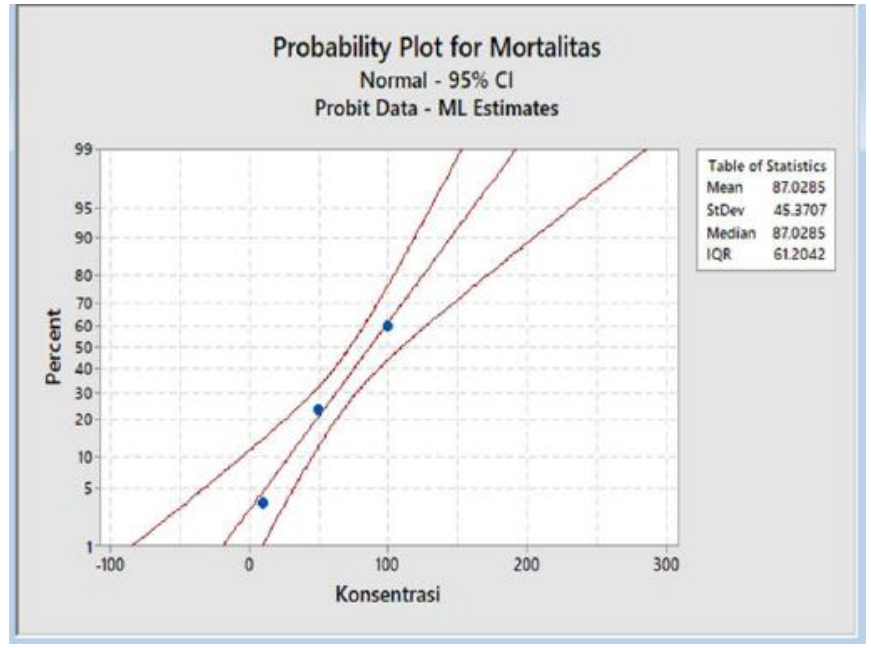

Fig.3. $L C_{50}$ value of ethanol extract of lavender leaf samples on Ae. aegypti larvae after 24 hours of treatment.

Table 2 and Figure 3 present the $\mathrm{LC}_{50}$ or Mean Lethal Concentration values of the ethanol extract of lavender leaves based on the results of Probit Analysis. The test results show the value of the $\mathrm{LC}_{50}$ mortality concentration of Ae. aegypti is by giving a concentration of 245,802 $\mathrm{ppm}$. Thus, the concentration figure of $245,802 \mathrm{ppm}$ is the concentration of the lavender leaf ethanol extract which is the most effective for killing Ae. aegypti as much as $50 \%$ for 24 hours of treatment. According to the toxicity criteria based on the Australian Petroleum Energy Association (1994) the concentration of 245,802 from the ethanolic extract of lavender leaves or $\left(\mathrm{LC}_{50}=245,802 \mathrm{ppm}\right)$ at 24 hours of observation was included in the criteria for Toxic Poisoning. 


\section{CONCLUSION}

\section{Conclusion}

1. There is a significant difference between the mortality rate of Ae. aegypti at various concentrations of lavender leaf ethanol extract ranging from $0 \mathrm{ppm}$ to $1000 \mathrm{ppm}$.

2. The results of the test of biolarvicide activity on the larvae of Ae. aegypti showed that lavender leaf ethanol extract was active as a larvicidal agent and effectively killed Ae. aegypti with a mortality concentration value of $\mathrm{LC}_{50}=44.7526 \mathrm{ppm}$. included in the criteria for Toxic Poison.

\section{Suggestion}

1. It is necessary to separate and further identify the ethanolic extract of lavender leaves using chromatography and GC-MS spectrometer techniques.

2. The results of the separation, purification and identification of the compounds contained in the ethanol extract of lavender leaves were tested for their biolarvicidal activity on the larvae of Ae. aegypti to obtain the most toxic isolates as an ingredient in the formula for anti mosquito dengue fever.

\section{ACKNOWLEDGEMENTS}

The researchers and team thank the Manado State University through the chairman of the Institute for Research and Community Service (LPPM) Dr. Rymond J. Rumampuk,M.Si who has sponsored this research through UNIMA PNBP funds in 2021.

\section{REFERENCES}

[1] Alfrits Komansilan, Ni Wayan Suriani, Helen Lawalata. 2017. Test Toxic Tuba Root Extract as a Natural Insecticide on Larvae of Aedesaegypti Mosquito Vector of Dengue Fever. International Journal of ChemTech Research. Vol.10 No.4, pp 522-528,

[2] Khwerissat, 2009. Lavender. Http://www. Author stream.com/ presentation/ farawela235217lavendereducation-ppt-powerpoin/. Diakses 14 januari 2017

[3] Komansilan A, Abdul L. A, Yanuwiadi B, and Kaligis D.A. 2012, Isolation and Identification of Biolarvicide from Soursop (Annonamuricata Linn) Seeds to Mosquito (Aedes aegypti) Larvae. International Journal of Engineering \& Technology IJET-IJENS Vol: 12 No: 03 pp 28-32

[4] Komansilan A. and Suriani,N W. 2016. Effectiveness of Seed Extract Hutun (Barringtonia asiatica KURZ), on Larva Aedes aegypti Vector Disease Dengue Fever. International Journal of ChemTech Research Vol.9, No.04 pp 617-624

[5] Kundra. 1981. Dinamika Populasi. IPB, Bogor

[6] Lekitoo M, 2009. Respon nyamuk Aedes aegypti terhadap kairomon tanaman lavender (Lavandula angostifolia).
Skripsi Fakultas Matematika dan Ilmu Pengetahuan Alam Universitas Pattimura. Ambon.

[7] Maria Nindatua, Novita L. Tuhumury, Martha Kaihena. 2011. PENGEMBANGAN EKSTRAK ETANOL DAUN LAVENDER (Lavandula angustifolia) SEBAGAI ANTI NYAMUK VEKTOR FILARIASIS Culex $s p$. Molucca Medica, Volume 4, Nomor 1, Oktober 2011, hlm. 19-27

[8] World Health Organization (2005). Pencegahan dan pengendalian Dengue dan Demam Berdarah Dengue. Penerbit buku kedokteran (EGC). Jakarta. 